\title{
Matched population comparison of visual outcomes and patient satisfaction between 3 modalities for the correction of low to moderate myopic astigmatism
}

\author{
This article was published in the following Dove Press journal: \\ Clinical Ophthalmology \\ 3 July 2017 \\ Number of times this article has been viewed
}

\section{Sri Ganesh \\ Sheetal Brar \\ Archana Pawar}

Phacorefractive Department, Nethradhama Superspeciality Eye Hospital, Bengaluru, Karnataka, India
Correspondence: Sheetal Brar Phacorefractive Department, Nethradhama Superspeciality Eye Hospital, 256/I4, Kanakapura Main Road, 7th Block, Jayanagar, Bengaluru 560082, Karnataka, India Tel +9| 9591002092

Emailbrar_sheetal@yahoo.co.in
Purpose: To compare toric implantable collamer lens (T-ICL), femto-LASIK, and ReLEx SMILE for the treatment of low to moderate myopic astigmatism in terms of long-term visual and refractive outcomes and predictability of astigmatic correction.

Materials and methods: The study included 30 eyes from 30 patients between the age groups of 21 and 40 years, undergoing bilateral surgery with any of the three procedures - T-ICL, femto-LASIK, or ReLEx SMILE - for correction of myopic astigmatism within the range of -3 to $-8 \mathrm{D}$ spherical equivalent $(\mathrm{SE})$, with a minimum astigmatism of $-0.75 \mathrm{D}$. Patients were followed up at day 1, 1 month, 6 months, and 1 year.

Results: At 1 year, the mean cylinder reduced to $-0.21 \pm 0.28,-0.17 \pm 0.36$, and $-0.22 \pm 0.28 \mathrm{D}$ in the T-ICL, femto-LASIK, and ReLEx SMILE group, respectively. The predictability of astigmatism correction was comparable, with no statistically significant difference between the 3 groups $(P>0.05)$. A total of $97 \%$ of eyes in ReLEx SMILE achieved a uncorrected distance visual acuity of 20/20 or better, compared to T-ICL (93\%) and FS-LASIK (90\%). However, gain in lines of corrected distant visual acuity (CDVA) was maximum in T-ICL group (60\%). Four eyes in the femto-LASIK group had loss of CDVA by one line. Three eyes required exchange due to high vault and rotation of the T-ICL, which did not affect the final outcome.

Conclusion: All 3 modalities were effective for myopic astigmatism at the end of 1 year. Quality of vision and patient satisfaction with T-ICL and ReLEx SMILE were similar and better than FS-LASIK. However, slight chances of postoperative rotation and exchange exist with T-ICL, which warrant thorough preoperative planning.

Keywords: toric implantable collamer lens, femtosecond LASIK, ReLEx SMILE, myopic astigmatism

\section{Introduction}

In the present era of modern refractive surgery, various modalities are available for the surgical correction of myopia and myopic astigmatism depending upon the grade of refractive error. Generally, an excimer-based corneal procedure such as LASIK or PRK is preferred for low to moderate myopia, while an implantable collamer lens (ICL) is indicated for higher degrees of myopia, outside the safety limit of corneal correction. ${ }^{1,2}$ Although the latter is US Food and Drug Administration (FDA) approved to correct myopia ranging from -3.00 to -20.00 diopters (D), being an intraocular procedure, its use is generally restricted to patients with high refractive error beyond the range of corneal procedures to prevent the risk of corneal ectasia. ${ }^{3}$ However, the validity of use 
of ICL in lower degrees of myopia and myopic astigmatism as a primary treatment modality has already been verified. ${ }^{4}$ For the correction of myopic astigmatism in particular, both LASIK and toric implantable collamer lens (T-ICL) have been shown to be safe and effective in various studies. ${ }^{5-8}$ It was found that LASIK was effective for correction of astigmatism up to $4.5 \mathrm{D},{ }^{6}$ while T-ICL provided safe and stable results with astigmatism up to $7 \mathrm{D}$ in long-term studies. ${ }^{8}$

Recently, ReLEx SMILE has been introduced as a relatively new, all-femtosecond laser procedure for correction of myopia and myopic astigmatism, in which an intrastromal lenticule is extracted through a small incision (2-4 mm). Data from various studies suggest that this modality is a safe and effective method to correct varying degrees of myopia, with the advantages of minimum postoperative discomfort and restrictions, less dry eye, and probably better biomechanics compared to LASIK. ${ }^{9,10}$ Studies comparing the results of astigmatism correction with ReLEx SMILE and LASIK, however, showed better outcomes with LASIK, most likely due to non-availability of iris registration and eye tracker in the current version of the femtosecond laser used for the ReLEx SMILE procedure. ${ }^{11,12}$ However, similar comparison studies have not been reported between T-ICL and ReLEx SMILE.

Correcting astigmatism accurately with refractive procedures is still a challenge. Whether astigmatism should be corrected on the cornea or inside the eye with a T-ICL is also a matter of ongoing debate, especially when there is no contraindication to a cornea-based surgical procedure.

Through this prospective study, we investigated three currently available and popular surgical modalities - T-ICL, femtosecond LASIK, and ReLEx SMILE - for the treatment of low to moderate myopic astigmatism. We also compared visual and refractive outcomes, safety, efficacy, predictability, and stability of astigmatic correction in this 1 year prospective clinical trial.

\section{Materials and methods}

This prospective, interventional, non-randomized, singlecenter study was approved by the institutional ethics committee of Nethradhama Superspeciality Eye Hospital, Bengaluru, and was performed in accordance with the tenets of the Declaration of Helsinki. All study participants provided written informed consent and ensured a long term follow-up.

The study included 30 eyes from 30 patients undergoing bilateral surgery with any of the following three procedures - T-ICL (group A), femto-LASIK (group B), or ReLEx SMILE (group C) - for correction of low to moderate myopic astigmatism. One eye from each patient was included to ensure uniformity and eliminate bias in the interpretation of results.

Common inclusion criteria for all 3 groups were as follows: age between 21 and 40 years, myopic astigmatism within the range of -3 to $-8 \mathrm{D}$ spherical equivalent $(\mathrm{SE})$ with a minimum astigmatism of $-0.75 \mathrm{D}$, stable refraction $(<0.5 \mathrm{D}$ change in past 12 months), corrected distant visual acuity (CDVA) of 20/30 or better, healthy tear film and ocular surface, absence of corneal ectatic diseases, corneal scars, absence of any retinal pathology, and assured follow-ups. Patients using soft and rigid contact lenses were instructed to discontinue their lenses at least for 1 and 3 weeks, respectively, prior to the topographic evaluation. For patients planned for T-ICL, a minimum anterior chamber depth of $2.8 \mathrm{~mm}$ and endothelial cell count of 1,500 cells $/ \mathrm{mm}^{2}$ were ensured.

Patients with unstable refraction, pregnancy, or using medications such as hormonal preparations, anti-depressants, oral steroids, and immunosuppressants were excluded from the study.

\section{Preoperative evaluation}

All patients underwent a thorough preoperative evaluation including anterior and posterior segment examination, assessment of uncorrected and corrected distance visual acuity, corneal topography using Pentacam HR (Oculus Optikgeräte GmbH, Wetzlar, Germany) and Orbscan II (Bausch \& Lomb, Rochester, NY, USA), contrast sensitivity using functional acuity contrast test (Stereo Optical Co. Inc., Chicago, IL, USA), abberometry (iTrace; Tracey Technologies, Houston, TX, USA), specular microscopy (Tomey, Nagoya, Japan), and dry eye evaluation (Schirmer 1 and tear film breakup time [TBUT]).

\section{Surgical technique}

All surgeries were performed by a single experienced refractive surgeon (SG) under topical anesthesia using the same technique in both the eyes.

\section{T-ICL (group A)}

T-ICL power calculation was performed by the manufacturer (STAAR Surgicals, Monrovia, CA, USA) using a modified vertex formula. The size of the ICL was selected on the basis of the horizontal corneal diameter and anterior chamber depth measured with scanning-slit topography (Orbscan IIz). All patients underwent implantation of the Visian Toric-ICL V4c model (STAAR Surgicals) using the standard surgical technique. ${ }^{13}$ Preoperatively $0^{\circ}-180^{\circ}$ axis was marked at the slit lamp. Following this, T-ICL was inserted through a temporal, 
$2.8 \mathrm{~mm}$ limbal incision and carefully positioned posterior to iris using a Vukich's manipulator in the intended axis as per the rotation diagram provided by the manufacturer.

\section{Femto-LASIK (group B)}

Visumax femtosecond laser (Carl Zeiss Meditec AG, Jena, Germany) was used to create superior hinged flaps with a thickness of 100-120 $\mu \mathrm{m}$, flap diameter of 7.5-8.0 mm, optical zone between 6 and $7 \mathrm{~mm}$, and a transition zone of $8.2 \mathrm{~mm}$. The ablation was performed using an MEL 90 excimer laser (Carl Zeiss Meditec AG) with iris-recognition software using the iris pattern image taken preoperatively with a wavefront aberration-supported corneal ablation analyzer (Carl Zeiss Meditec AG). A standard profile ablation (non-wavefront) was used to correct sphere and refractive cylinder with the aim of achieving emmetropia. An active eye tracker was used to ensure accurate ablation on the center of the pupil. Mean optical zone used was $6.3 \pm 0.21 \mathrm{~mm}$.

\section{ReLEx SMILE (group C)}

The procedure was performed with VisuMax femtosecond laser (Carl Zeiss Meditec AG), with a pulse repetition rate of $500 \mathrm{KHz}$, an optical zone of $6.5-7 \mathrm{~mm}$, a cap thickness of $120 \mu \mathrm{m}$, and a superior incision of $2 \mathrm{~mm}$, using the standard surgical technique. ${ }^{14}$ The treatment was centered on the visual axis. Mean optical zone used was $6.5 \pm 0.23 \mathrm{~mm}$.

Preoperatively, the limbus was marked in an axis ranging from $0^{\circ}$ to $180^{\circ}$ axis with an infrared transmitting dye (Viscot surgical skin marker 1436; Viscot Medical) using either a marker pen or Ganesh bubble marker (Epsilon Surgicals; Figure S1A) in the upright position. The patient was then positioned under the VisuMax FS laser and instructed to look into the green flashing fixation light. Once proper centration was achieved, the eye was docked to the patient interface followed by application of suction. At this point, the extent of cyclotorsion was determined using the reticule in the eyepiece and any cyclotorsion was manually compensated by gently rotating the contact glass to align the horizontal marks on the eye to an axis ranging from $0^{\circ}$ to $180^{\circ}$ of the reticule (Figure S1B-D). Once both were aligned, the active laser process was started to create the refractive lenticule and surgery completed in routine manner.

No intraoperative complications were observed in any of the eyes operated in the three study groups.

Postoperative examinations were conducted at day 1, 1 week, 1 month, 6 months, and 1 year. At each follow-up visit from 1 month onward, assessment of uncorrected visual acuity (UDVA), manifest refraction, CDVA, topography, contrast sensitivity, abberometry, and dry eye evaluation with TBUT was performed for all study groups. Endothelial cell counts were repeated for all eyes at 1 year postoperative visit. For the T-ICL group, in addition to these tests, spectral domain anterior segment OCT (Optovue ${ }^{\circledR}$; iVue, Fremont, CA, USA) was also performed for measurement of the postoperative vault of the T-ICL on all visits.

\section{Statistical and graphical analysis}

Statistical analysis was performed using SPSS software (version 17). Analysis of variance (ANOVA) test was carried out for intergroup comparison, and paired $t$-test was used for intragroup comparison of means. A $P$-value of 0.05 or less was considered statistically significant. Standard graphs were generated using Datagraph-med 5.20 software. Vector analysis was performed using Alpins Statistical System for Ophthalmic Refractive Surgery Techniques (ASSORT) software that uses the Alpins method for vectorial analysis of astigmatism.

\section{Results}

The groups were appropriately matched with respect to age, $\mathrm{SE}$, contrast sensitivity scores, and TBUT $(P>0.05)$. However, the mean cylinder was significantly higher in T-ICL group $(-1.88 \mathrm{D} \pm 0.88)$ compared to FS-LASIK $(-1.42 \mathrm{D} \pm 0.99)$ and $\operatorname{ReLEx} \operatorname{SMILE}(-1.08 \mathrm{D} \pm 0.38)(P<0.05)$. Also, the mean preoperative CDVA was lower in the T-ICL group $(0.032 \pm 0.048$ Log MAR) compared to other 2 groups $(P<0.05)$ (Table 1$)$. This was due to the inclusion of 2 eyes with mild amblyopia (preop CDVA 20/30) in this group, while all eyes in the other 2 groups had a preop CDVA of 20/20 or better. The higher order aberrations (HOAs) were also significantly high in the T-ICL group compared to the other 2 groups (Table 1).

\section{Safety (postoperative CDVA/preoperative CDVA)}

At 1 year, in the FS-LASIK group, 4 eyes showed loss of CDVA by one line. T-ICL group had the highest percentage of eyes $(60 \%)$ with gain in lines of CDVA by one or more lines compared to FS-LASIK (40\%) and ReLEx SMILE group (50\%), respectively. Correspondingly, the safety indices were 1.24, 1.15, and 1.11 for groups $\mathrm{A}, \mathrm{C}$, and $\mathrm{B}$, respectively (Figure 1).

\section{Efficacy (postoperative uncorrected distance visual acuity [UDVA]/ preoperative CDVA)}

At 1 year, 97\% eyes in group C (ReLEx SMILE), 93\% eyes in T-ICL, and $90 \%$ eyes in FS-LASIK group had UDVA of 
Table I Preoperative baseline characteristics of patients included in the 3 study groups

\begin{tabular}{lllll}
\hline Mean \pm SD & Group A (T-ICL) & Group B (FS-LASIK) & Group C (ReLEx SMILE) & P-value \\
\hline Age (years) & $26.43 \pm 2.4$ & $27.63 \pm 5.04$ & $28.93 \pm 5.17$ & 0.096 \\
SE (D) & $-5.98 \mathrm{D} \pm 1.15$ & $-5.43 \mathrm{D} \pm 1.22$ & $-4.58 \mathrm{D} \pm 1.59$ & $-17.08 \mathrm{D} \pm 0.38$ \\
CYL (D) & $-1.88 \mathrm{D} \pm 0.88$ & $-1.42 \mathrm{D} \pm 0.99$ & $-0.01 \pm 0.043$ & $0.00 I^{*}$ \\
CDVA (Log MAR) & $0.032 \pm 0.048$ & $0.007 \pm 0.016$ & $2,951 \pm 330$ & $0.000^{*}$ \\
ECD (cells/mm $)$ & $3,087 \pm 245$ & $3.011 \pm 243$ & $11.26 \pm 1.22$ & 0.510 \\
TBUT (sec) & $11.50 \pm 1.27$ & $11.43 \pm 1.47$ & $0.120 \pm 0.06$ & 0.784 \\
HOA (RMS, $\mu)$ & $0.260 \pm 0.14$ & $0.115 \pm 0.05$ & & $0.000^{*}$ \\
FACT (cpd) & & & $1.75 \pm 0.06$ & 0.157 \\
A (I.5) & $1.79 \pm 0.5$ & $1.76 \pm 0.09$ & $1.75 \pm 0.08$ & 0.392 \\
B (3) & $1.76 \pm 0.07$ & $1.73 \pm 0.13$ & $1.91 \pm 0.09$ & 0.211 \\
C (6) & $1.93 \pm 0.09$ & $1.87 \pm 0.19$ & $1.58 \pm 0.16$ & 0.890 \\
D (I2) & $1.60 \pm 0.10$ & $1.58 \pm 0.22$ & $1.07 \pm 0.27$ & 0.814 \\
E (I8) & $1.08 \pm 0.15$ & $1.11 \pm 0.24$ & \\
\hline
\end{tabular}

Note: *P-value calculated using ANOVA.

Abbreviations: SD, standard deviation; T-ICL, toric implantable collamer lens; FS-LASIK, femtosecond LASIK; SE, spherical equivalent; CYL (D), cylinder (dioptres); CDVA, corrected distance visual acuity; ECD, endothelial cell density; TBUT, tear film breakup time; HOA (RMS), higher order aberrations (root mean square); FACT, functional contrast acuity test; ANOVA, analysis of variance.

20/20 or better (Figure 2). However, the efficacy index was highest in T-ICL group (1.12) compared to ReLEx SMILE (1.06) and FS-LASIK group (1.02). Mean postop UDVA (Log MAR) was marginally better in ReLEx SMILE group compared to other two groups; however, the differences were not significant $(P<0.05$ at all visits). All the 3 groups showed an improvement in UDVA over time. Similar trends were observed in mean postop CDVA (Table 2).

\section{Refractive outcomes}

SE correction was comparable between T-ICL and ReLEx SMILE groups at 1 month postop. However, mild undercorrection was observed in both femto-LASIK and ReLEx SMILE groups, while the SE remained fairly stable in

\section{Change in CDVA: percentage "safety"}

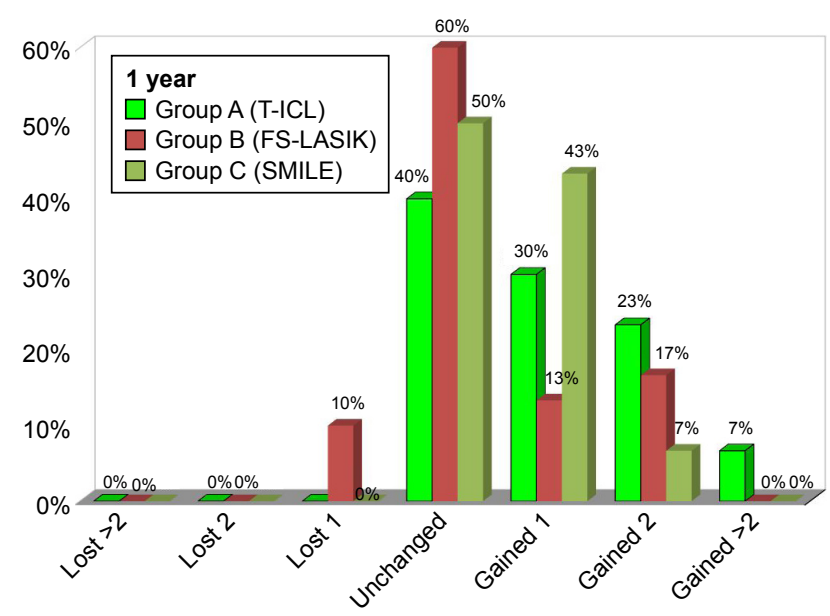

Figure I Safety (gain/loss in lines of CDVA) of the 3 study groups at I year. Abbreviations: CDVA, corrected distant visual acuity; T-ICL, toric implantable collamer lens; FS-LASIK, femtosecond LASIK.
T-ICL group over time. However, differences between the groups were not significant at any follow-up visits $(P<0.05)$ (Table 2). SE predictability was within $\pm 0.5 \mathrm{D}$ in $93 \%$ eyes in ReLEx SMILE group compared to $90 \%$ eyes in T-ICL and $77 \%$ eyes in femto-LASIK group. All 3 groups showed SE predictability within $\pm 1 \mathrm{D}$ in $100 \%$ eyes (Figure 3 ). Predictability of astigmatic correction was slightly better with FS-LASIK with $93 \%$ eyes being within $\pm 0.5 \mathrm{D}$ at 1 year postop compared to T-ICL and ReLEx SMILE groups $(90 \%$ eyes within $\pm 0.5 \mathrm{D}$ for both groups). All eyes in all groups had cylinder predictability within \pm 1 D (Figure 4). All 3

\section{Cumulative UDVA (\%)}

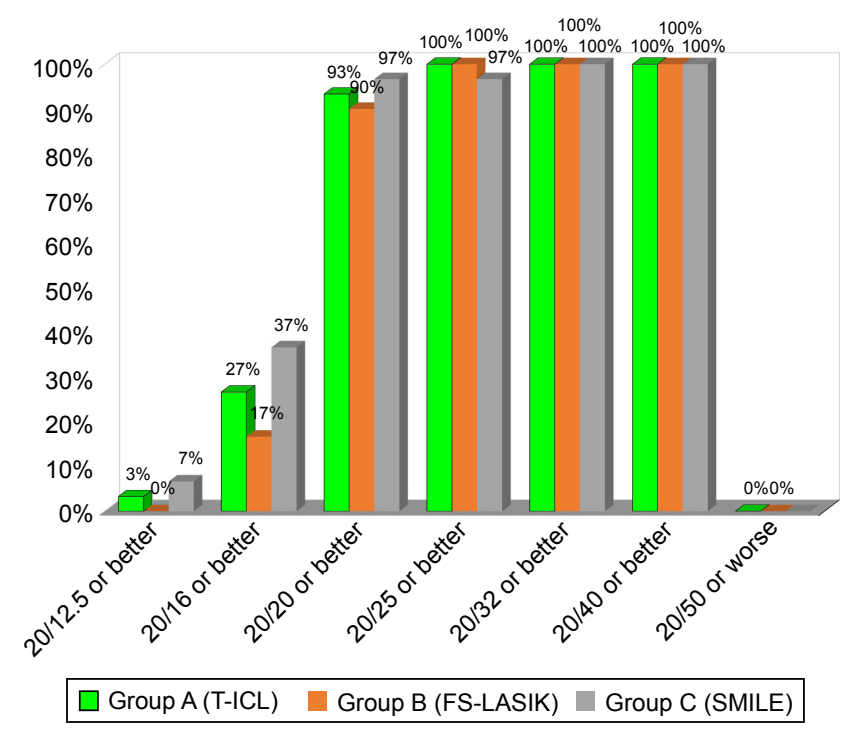

Figure 2 Cumulative UDVA (\% of eyes 20/20 or better) in the 3 study groups at I year.

Abbreviations: UDVA, uncorrected distance visual acuity; T-ICL, toric implantable collamer lens; FS-LASIK, femtosecond LASIK. 
Table 2 Postoperative visual and refractive outcomes with the 3 surgical modalities at I year

\begin{tabular}{|c|c|c|c|c|}
\hline Parameter & Group A (T-ICL) & Group B (FS-LASIK) & Group C (SMILE) & $P$-value \\
\hline \multicolumn{5}{|l|}{ UDVA (Log MAR) } \\
\hline I month & $-0.002 \pm 0.055$ & $0.0073 \pm 0.06$ & $-0.02 I \pm 0.062$ & 0.115 \\
\hline 6 months & $-0.009 \pm 0.043$ & $-0.002 \pm 0.054$ & $-0.028 \pm 0.055$ & 0.230 \\
\hline I year & $-0.022 \pm 0.021$ & $-0.011 \pm 0.069$ & $-0.027 \pm 0.069$ & 0.626 \\
\hline \multicolumn{5}{|l|}{ CDVA (Log MAR) } \\
\hline Preoperative & $0.032 \pm 0.048$ & $0.007 \pm 0.016$ & $-0.008 \pm 0.038$ & $0.000^{*}$ \\
\hline I month & $-0.035 \pm 0.047$ & $-0.019 \pm 0.065$ & $-0.04 \pm 0.067$ & 0.390 \\
\hline 6 months & $-0.055 \pm 0.066$ & $-0.042 \pm 0.088$ & $-0.052 \pm 0.076$ & 0.780 \\
\hline I year & $-0.07 I \pm 0.079$ & $-0.06 \pm 0.10$ & $-0.064 \pm 0.082$ & 0.880 \\
\hline \multicolumn{5}{|l|}{ SE (D) } \\
\hline Preoperative & $-5.98 \pm 1.15$ & $-5.43 \pm 1.22$ & $-4.58 \pm 1.59$ & 0.063 \\
\hline I month & $-0.143 \pm 0.22$ & $-0.159 \pm 0.43$ & $-0.137 \pm 0.20$ & 0.962 \\
\hline 6 months & $-0.159 \pm 0.23$ & $-0.209 \pm 0.46$ & $-0.17 \mid \pm 0.20$ & 0.823 \\
\hline I year & $-0.164 \pm 0.20$ & $-0.225 \pm 0.43$ & $-0.208 \pm 0.24$ & 0.733 \\
\hline \multicolumn{5}{|l|}{ CYL (D) } \\
\hline Preoperative & $-1.88 \pm 0.88$ & $-1.42 \pm 0.99$ & $-1.08 \pm 0.38$ & $0.00 I^{*}$ \\
\hline I month & $-0.191 \pm 0.45$ & $-0.166 \pm 0.31$ & $-0.183 \pm 0.23$ & 0.943 \\
\hline 6 months & $-0.208 \pm 0.32$ & $-0.166 \pm 0.33$ & $-0.191 \pm 0.23$ & 0.863 \\
\hline I year & $-0.216 \pm 0.28$ & $-0.175 \pm 0.36$ & $-0.225 \pm 0.28$ & 0.803 \\
\hline
\end{tabular}

Notes: *P-value calculated using ANOVA. Data presented as mean \pm SD.

Abbreviations: UDVA, uncorrected distance visual acuity; CDVA, corrected distance visual acuity; SE (D), spherical equivalent (diopters); CYL (D), cylinder (diopters); T-ICL, toric implantable collamer lens; FS-LASIK, femtosecond LASIK; ANOVA, analysis of variance; SD, standard deviation.

groups showed a slight undercorrection of cylinder at 1 year, which was not statistically significant from 1 month values $(P<0.05$; Figure 5$)$ Vector analysis of astigmatism showed that the mean target-induced astigmatism (TIA) was statistically significantly high in the T-ICL group compared to the other 2 groups $(P=0.002)$. However, there was no statistically

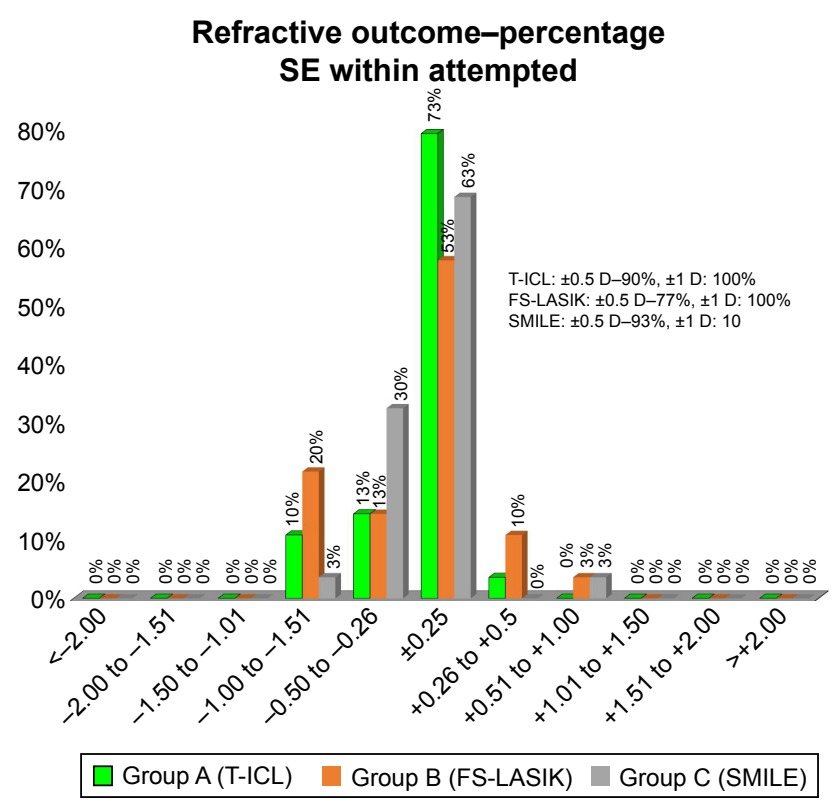

Figure 3 Predictability of SE correction with the 3 treatment modalities at I year. Abbreviations: SE, spherical equivalent; $\mathrm{T}-\mathrm{ICL}$, toric implantable collamer lens; FS-LASIK, femtosecond LASIK. significant difference in the outcomes of surgically induced astigmatism, TIA, difference vector, correction index, and index of success between the 3 study groups $(P>0.05$ for all parameters; Table 3).

\section{Contrast sensitivity and aberrations}

At 1 year, mean photopic contrast sensitivity scores were significantly better in T-ICL group among the 3 groups $(P<0.05)$. The scores were in fact better than the preoperative values for spatial frequencies of 6 and $18 \mathrm{cpds}$. On the other hand, the mean scores were significantly lower in LASIK group; however, they were comparable to preoperative values in ReLEx SMILE group (Figure 6, Table 4).

At 1 year, the T-ICL group showed a significant improvement in the HOAs, which had actually reduced $(P=0.007)$, whereas in the FS-LASIK group, the HOAs had significantly increased compared to preoperative values $(P=0.038)$. In the ReLEx SMILE group, HOAs marginally increased, but the difference was not statistically significant compared to preop values ( $P=0.68$; Table 4$)$.

\section{Endothelial cell count and dry eye assessment}

There was no significant change in the endothelial cell count in either of the study groups compared to preoperative values at 1 year (Table 4). 
Group A (T-ICL)

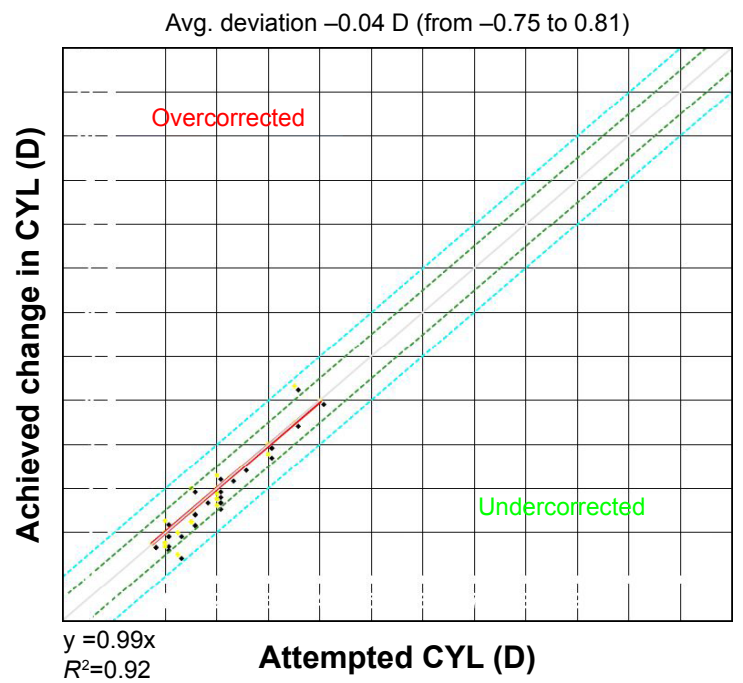

Group B (FS-LASIK)

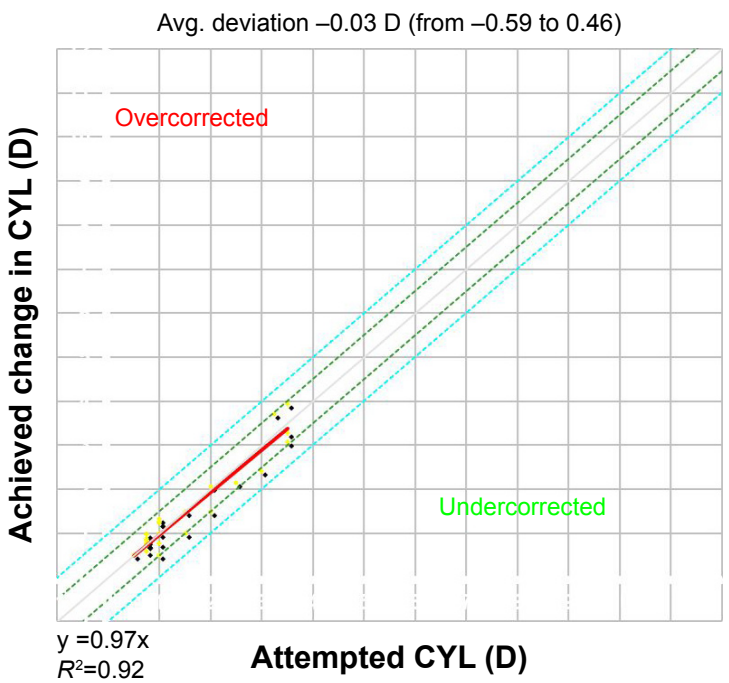

Group C (ReLEx SMILE)

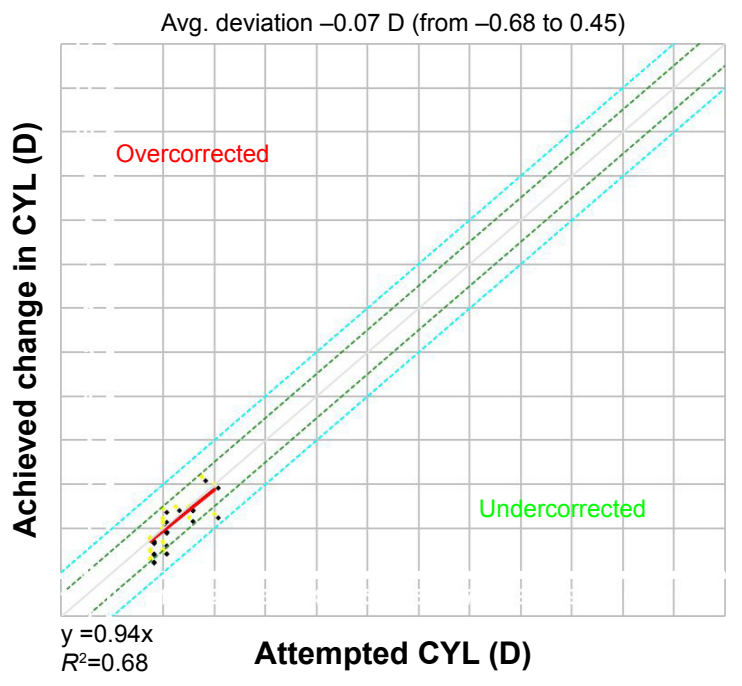

Figure 4 Predictability - scatter (attempted vs achieved) astigmatism correction with the 3 modalities at I year. Abbreviations: CYL (D), cylinder (diopters); T-ICL, toric implantable collamer lens; FS-LASIK, femtosecond LASIK.

Dry eye evaluation revealed a significant decrease in TBUT scores in FS-LASIK group at 1 year $(P=0.00)$, while they did not show a significant change in the T-ICL group ( $P=0.34$ ) compared to the preoperative scores. Although the mean TBUT scores in the SMILE groups showed a transient, non-significant reduction at 1 month, they improved over time and were comparable to preoperative values at 1 year ( $P=0.06$; Table 4).

\section{Patient satisfaction and long-term complications}

Up to $60 \%$ patients in the T-ICL group reported symptoms of dysphotopsia in the immediate postop period, and the severity gradually reduced over time. In the SMILE group, most patients complained about slight foggy vision initially, and their vision settled by 1 month. At the end of 1 year, patients in the T-ICL and SMILE group reported excellent satisfaction with their quality of vision, but LASIK patients reported lower satisfaction due to persistent dryness and need for frequent instillation of lubricant eye drops.

In the T-ICL group, 3 eyes required T-ICL exchange due to frequent rotation by $>30^{\circ}$ and excessive high vault in the postoperative period. However, no eye in this group suffered from any sight threatening complication such as cataract, retinal detachment, endophthalmitis, or glaucoma. In the FS-LASIK group, 2 eyes had loss of CDVA due to microwrinkles. However, no postoperative complications were observed in the ReLEx SMILE group (Table 2). 

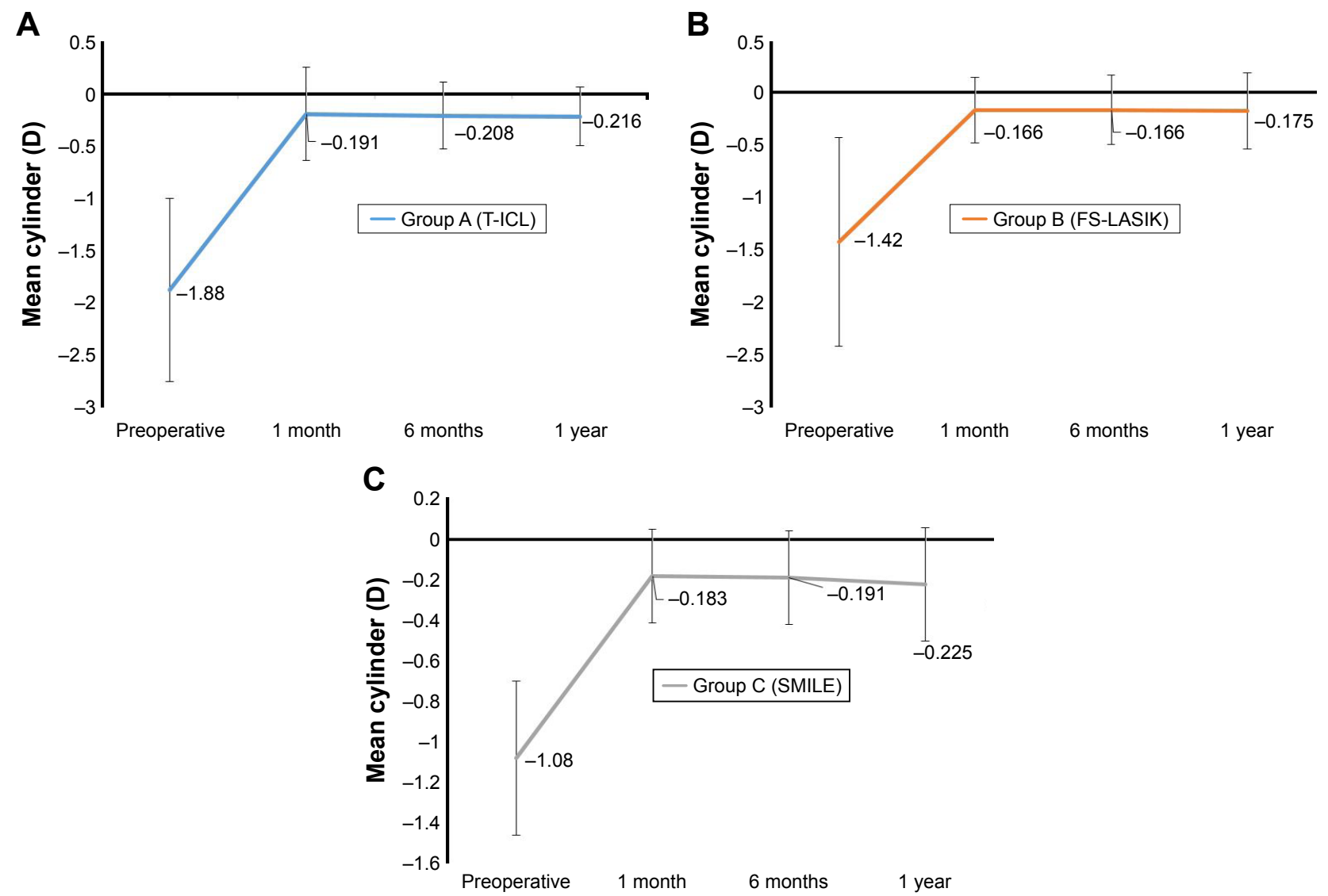

Figure 5 Stability of astigmatism correction with the 3 treatment modalities over time. Notes: (A) T-ICL group; (B) FS-LASIK group; (C) ReLEx SMILE group.

Abbreviations: T-ICL, toric implantable collamer lens; FS-LASIK, femtosecond LASIK.

\section{Discussion}

Outcomes of myopic astigmatism with T-ICL, femto-LASIK, and ReLEx SMILE have been previously reported. However, to the best of our knowledge, no study has compared these three modalities for astigmatism correction and long-term safety, efficacy, visual quality, and complications.

In the present study, all the 3 groups were comparable in terms of mean postoperative UDVA, DCVA, SE, and cylinder correction, indicating that all the 3 modalities were effective with no statistically significant differences between the groups for these parameters at 1 year (Table 1). However, the UDVA and CDVA were marginally better with
ReLEx SMILE, and T-ICL, respectively, in comparison with FS-LASIK. On the other hand, in terms of predictability of astigmatism correction, FS-LASIK scored slightly better compared to both T-ICL and SMILE groups.

These results were consistent with the study by Hasegawa et al, ${ }^{15}$ who reported a higher predictability of correction with FS-LASIK compared to toric phakic IOL (pIOL) in eyes with moderate refractive cylinder (1.50-2.75 D) compared to high cylinder $>3 \mathrm{D}$, where toric $\mathrm{pIOL}$ was found to have better predictability. The authors speculated that this difference was due to difference in the units of refractive cylinder correction since the refractive cylinder power of the T-ICL

Table 3 Vector analysis of astigmatism between the 3 study groups at the end of I year

\begin{tabular}{lllll}
\hline Vector & Group A (T-ICL) & Group B (FS-LASIK) & Group C (SMILE) & P-value \\
\hline TIA & $1.63 \pm 0.77$ & $1.23 \pm 0.85$ & $0.99 \pm 0.37$ & $0.002 *$ \\
SIA & $1.55 \pm 0.91$ & $1.21 \pm 0.85$ & $1.02 \pm 0.43$ & 0.068 \\
DV & $-0.08 \pm 0.38$ & $-0.02 \pm 0.30$ & $0.03 \pm 0.18$ & 0.119 \\
CI & $0.93 \pm 0.27$ & $1.02 \pm 0.29$ & $1.02 \pm 0.20$ & 0.183 \\
IOS & $-0.06 \pm 0.27$ & $0.02 \pm 0.29$ & $0.02 \pm 0.20$ & 0.183 \\
\hline
\end{tabular}

Note: ${ }^{* P}$-value calculated by Kruskal-Wallis test.

Abbreviations: TIA, target-induced astigmatism; SIA, surgically induced astigmatism; DV, difference vector; Cl, correction index; IOS, index of success; T-ICL, toric implantable collamer lens; FS-LASIK, femtosecond LASIK. 

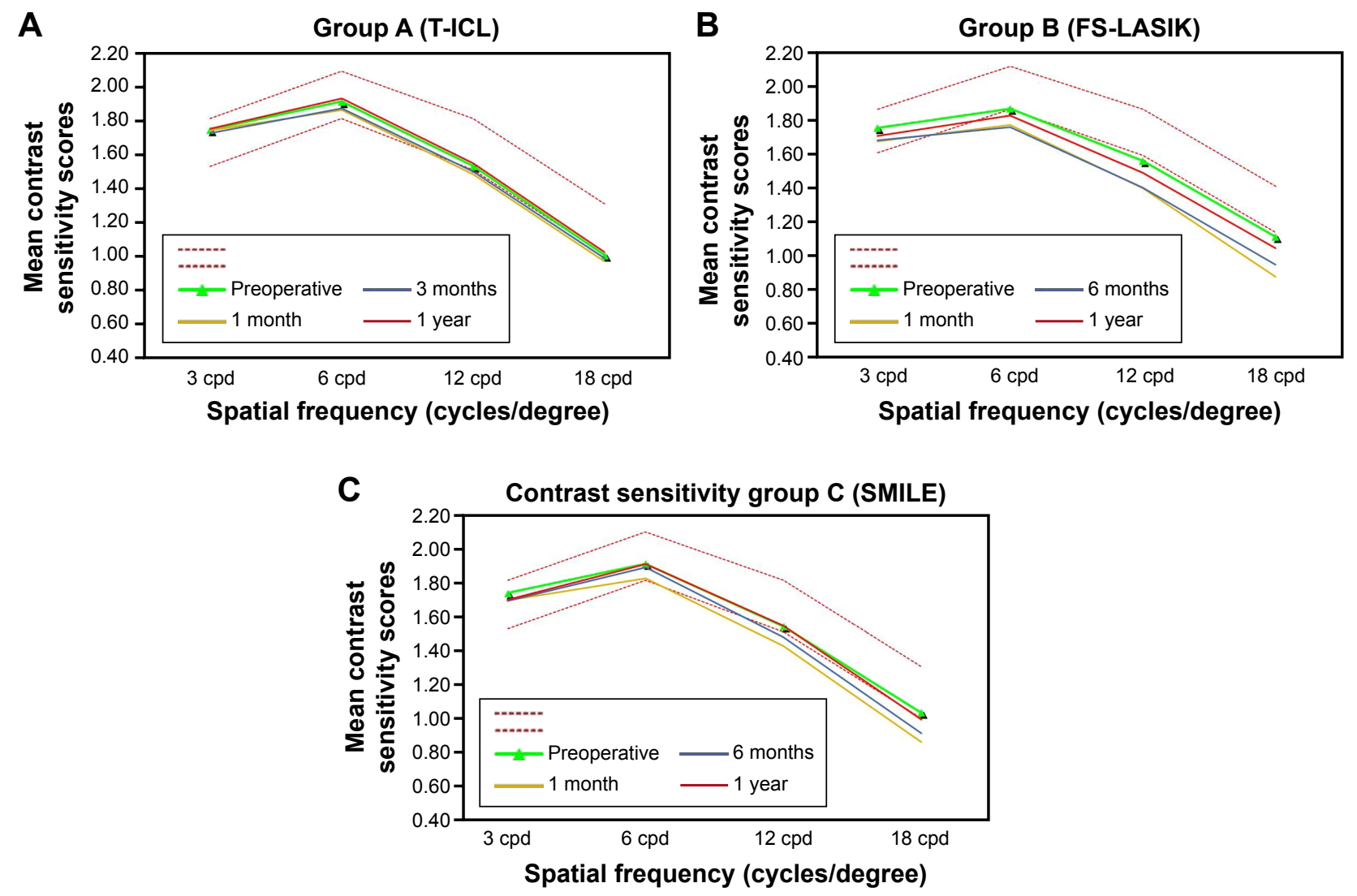

Figure 6 Contrast sensitivity with functional acuity contrast test (FACT) chart with (A) T-ICL, (B) FS-LASIK, and (C) ReLEx SMILE over time. Abbreviations: T-ICL, toric implantable collamer lens; FS-LASIK, femtosecond LASIK.

comes in $0.50 \mathrm{D}$ increments, while the corrective refractive cylinders used in LASIK are in $0.25 \mathrm{D}$ steps. ${ }^{15}$

Accurate compensation of potential static and dynamic rotation of the eye during treatment by the iris registration and active eye tracker software present in the MEL-90 excimer laser may also have contributed to slightly better outcomes of cylinder correction with FS-LASIK ${ }^{16}$ However, outcomes with T-ICL were shown to depend upon factors such as postoperative rotation, sizing issues, and accuracy of preoperative marking. ${ }^{17,18}$ In the event of significant $\left(>20^{\circ}\right)$ and recurrent rotation in the postoperative period, realignment and often an exchange of the T-ICL are warranted. ${ }^{19}$ This happened with 2 eyes in this series. However, the T-ICL maintained stable position after exchanging with one size bigger T-ICL, and did not rotate later in both cases.

Previous studies comparing astigmatism correction showed superior results with FS-LASIK compared to ReLEx SMILE. ${ }^{11}$ Pedersen et al have shown significant undercorrection of cylinder with SMILE over time. ${ }^{20}$ This was mainly attributed to non-compensation of errors of cyclotorsion and nonapplication of nomograms during the procedure. ${ }^{12}$ However, excellent results for astigmatism treatment were observed with ReLEx SMILE, which were far better compared to the published literature on SMILE. Since we performed a manual compensation of cyclotorsion and applied a 10\% nomogram (based on our experience and postop results), the accuracy of astigmatism correction was good and comparable to the other two modalities.

It has been previously demonstrated through studies using the optical quality analysis system that the hole ICL implantation appeared to be essentially equivalent in the optical quality variables to conventional ICL implantation, suggesting that the presence of the central artificial hole did not significantly affect the optical quality and the intraocular scattering after surgery. ${ }^{21}$ The contrast sensitivity following ICL as demonstrated by Igarashi et al did not significantly change, while there was a definite reduction in contrast after FS-LASIK. ${ }^{22}$ However, contrast sensitivity was found to be better with SMILE compared to FS-LASIK, as reported earlier. ${ }^{14}$ Also, the induction of aberrations with ICL was shown to be minimal and showed significant improvement in aberrations postoperatively. ${ }^{23}$ Both SMILE and FS-LASIK were reported to induce significant HOAs, ${ }^{24,25}$ although SMILE was shown to induce less aberrations compared to FS-LASIK. ${ }^{25}$ 
Table 4 Higher order aberrations, endothelial cell density, tear film breakup time, and contrast sensitivity values at I year with the 3 treatment modalities

\begin{tabular}{|c|c|c|c|c|}
\hline Parameter & T-ICL & FS-LASIK & SMILE & $P$-value* \\
\hline \multicolumn{5}{|l|}{ HOA (RMS, $\mu)$} \\
\hline Preoperative & $0.260 \pm 0.14$ & $0.115 \pm 0.05$ & $0.120 \pm 0.06$ & 0.000 \\
\hline I year & $0.150 \pm 0.07$ & $0.163 \pm 0.14$ & $0.126 \pm 0.07$ & 0.355 \\
\hline$P$-value ${ }^{\#}$ & 0.007 & 0.038 & 0.688 & \\
\hline \multicolumn{5}{|l|}{ ECD (cells/mm²) } \\
\hline Preoperative & $3,977 \pm 334$ & $3,030 \pm 28 \mathrm{I}$ & $2,845 \pm 666$ & 0.510 \\
\hline I year & $2,808 \pm 315$ & $3,025 \pm 310$ & $2,840 \pm 070$ & 0.683 \\
\hline$P$-value $\#$ & 0.068 & 0.922 & 0.972 & \\
\hline \multicolumn{5}{|l|}{ TBUT (sec) } \\
\hline Preoperative & $1 \mathrm{I} .50 \pm 1.27$ & II $.43 \pm 1.47$ & $11.26 \pm 1.22$ & 0.784 \\
\hline I year & $11.33 \pm 1.2$ & $9.4 \pm 1.47$ & $10.7 \pm 1.08$ & 0.000 \\
\hline$P$-value ${ }^{\#}$ & 0.344 & 0.000 & 0.064 & \\
\hline \multicolumn{5}{|l|}{ FACT (cpd) } \\
\hline \multicolumn{5}{|l|}{$\mathrm{A}(\mathrm{I} .5)$} \\
\hline Preoperative & $1.79 \pm 0.5$ & $1.76 \pm 0.09$ & $1.75 \pm 0.06$ & 0.157 \\
\hline I year & $1.79 \pm 0.60$ & $1.70 \pm 0.09$ & $\mathrm{I} .75 \pm 0.08$ & 0.000 \\
\hline$P$-value $\#$ & 0.573 & 0.007 & 0.988 & \\
\hline \multicolumn{5}{|l|}{ B (3) } \\
\hline Preoperative & $1.76 \pm 0.07$ & $1.73 \pm 0.13$ & $1.75 \pm 0.08$ & 0.392 \\
\hline I year & $1.78 \pm 0.08$ & $1.65 \pm 0.12$ & $1.72 \pm 0.10$ & 0.000 \\
\hline$P$-value ${ }^{\#}$ & 0.161 & 0.000 & 0.249 & \\
\hline \multicolumn{5}{|l|}{$C(6)$} \\
\hline Preoperative & $1.93 \pm 0.09$ & $1.87 \pm 0.19$ & $1.91 \pm 0.09$ & 0.211 \\
\hline I year & $1.97 \pm 0.06$ & $1.78 \pm 0.15$ & $1.92 \pm 0.13$ & 0.000 \\
\hline$P$-value $\#$ & 0.033 & 0.002 & 0.700 & \\
\hline \multicolumn{5}{|l|}{$D(12)$} \\
\hline Preoperative & $1.60 \pm 0.10$ & $1.58 \pm 0.22$ & $1.58 \pm 0.16$ & 0.890 \\
\hline I year & $1.61 \pm 0.12$ & $1.44 \pm 0.17$ & $1.58 \pm 0.16$ & 0.000 \\
\hline$P$-value ${ }^{\#}$ & 0.352 & 0.000 & 0.970 & \\
\hline \multicolumn{5}{|l|}{$E(18)$} \\
\hline Preoperative & $1.08 \pm 0.15$ & $\mathrm{I} . \mathrm{II} \pm 0.24$ & $1.07 \pm 0.27$ & 0.814 \\
\hline I year & $1.13 \pm 0.14$ & $0.97 \pm 0.19$ & $1.10 \pm 0.20$ & 0.002 \\
\hline$P$-value ${ }^{\#}$ & 0.004 & 0.000 & 0.579 & \\
\hline
\end{tabular}

Notes: ${ }^{*}$-value calculated using ANOVA; ${ }^{P}$-value calculated using paired $t$-test. Abbreviations: T-ICL, toric implantable collamer lens; FS-LASIK, femtosecond LASIK; HOA (RMS), higher order aberrations (root mean square); ECD, endothelial cell density; TBUT, tear film breakup time; FACT, functional contrast acuity test ANOVA, analysis of variance.

Interestingly, in this series, we observed that the HOAs increased after SMILE, but they were not statistically significant at 1 year. This may be due to use of relatively larger optical zones, minimal transition zone, and no loss of energy in periphery (cosine effect) in SMILE compared to LASIK.

Postoperative dry eye was least with T-ICL and was comparable to SMILE; however, it was significantly more with FS-LASIK even at the end of 1 year. Since both the former procedures involve minimal disruption of the corneal nerve fibers, postoperative dryness was practically non-existent compared to FS-LASIK. These observations corroborate with the results of previous studies on FS-LASIK and postoperative dry eye..$^{9,10}$
Due to these reasons, the optical quality with T-ICL was better than the other 2 corneal procedures, leading to highest patient satisfaction in the immediate postoperative period. However, at the end of 1 year, both T-ICL and SMILE had similar postop patient satisfaction regarding the quality of vision. ReLEx SMILE scored over FS-LASIK in terms of visual quality due to centration of treatment on visual axis, less induction of aberrations, and minimal postoperative dry eye. ${ }^{26}$

\section{Conclusion}

In this study, all the 3 modalities were found to be effective for myopic astigmatism at the end of 1 year. However, quality of vision and patient satisfaction with T-ICL and ReLEx SMILE were similar, both being better than FS-LASIK. Slight chances of postop rotation and exchange exist, which warrant thorough preoperative evaluation. Selecting the size of ICL based on sulcus-to-sulcus measurement in comparison to the traditional white-to-white measurements may prevent exchanges due to sizing issues.

\section{Acknowledgment}

This study was funded by STAAR Surgicals, Monrovia, CA, USA.

\section{Disclosure}

The authors report no conflicts of interest in this work.

\section{References}

1. Knorz MC, Wiesinger B, Liermann A, Seiberth V, Liesenhoff H. Laser in situ keratomileusis for moderate and high myopia and myopic astigmatism. Ophthalmology. 1998;105(5):932-940.

2. Barsam A, Allan BD. Excimer laser refractive surgery versus phakic intraocular lenses for the correction of moderate to high myopia. Cochrane Database Syst Rev. 2012;1:CD007679.

3. Huang D, Schallhorn SC, Sugar A, et al. Phakic intraocular lens implantation for the correction of myopia: a report by the American Academy of Ophthalmology. Ophthalmology. 2009;116(11):2244-2258.

4. Sanders D, Vukich JA. Comparison of implantable collamer lens (ICL) and laser-assisted in situ keratomileusis (LASIK) for low myopia. Cornea. 2006;25(10):1139-1146.

5. Sari ES, Pinero DP, Kubaloglu A, et al. Toric implantable collamer lens for moderate to high myopic astigmatism: 3-year follow-up. Graefes Arch Clin Exp Ophthalmol. 2013;251(5):1413-1422.

6. Reinstein DZ, Carp GI, Archer TJ, et al. Long-term visual and refractive outcomes after LASIK for high myopia and astigmatism from -8.00 to -14.25 D. J Refract Surg. 2016;32(5):290-297.

7. Reinstein DZ, Carp GI, Lewis TA, Archer TJ, Gobbe M. Outcomes for myopic LASIK with the MEL 90 excimer laser. J Refract Surg. 2015;31(5):316-321.

8. Elies D, Alonso T, Puig J, Gris O, Güell JL, Coret A. Visian toric implantable collamer lens for correction of compound myopic astigmatism. J Refract Surg. 2010;26(4):251-258.

9. Liu M, Chen Y, Wang D, et al. Clinical outcomes after SMILE and femtosecond laser-assisted LASIK for myopia and myopic astigmatism: a prospective randomized comparative study. Cornea. 2016;35(2):210-216. 
10. Zhang Y, Shen Q, Jia Y, Zhou D, Zhou J. Clinical outcomes of SMILE and FS-LASIK used to treat myopia: a meta-analysis. J Refract Surg. 2016;32(4):256-265.

11. Chan TC, Ng AL, Cheng GP, et al. Vector analysis of astigmatic correction after small-incision lenticule extraction and femtosecond-assisted LASIK for low to moderate myopic astigmatism. Br J Ophthalmol. 2016; 100(4):553-559.

12. Zhang J, Wang Y, Wu W, Xu L, Li X, Dou R. Vector analysis of low to moderate astigmatism with small incision lenticule extraction (SMILE): results of a 1-year follow-up. BMC Ophthalmol. 2015;15:8.

13. Brar S, Ganesh S, Pandey R. Incidence \& factors responsible for implantable collamer lens(ICL) explantation \& outcomes of further management - 5 year retrospective study. EC Ophthalmol. 2015;3(1):231-239.

14. Ganesh S, Gupta R. Comparison of visual and refractive outcomes following femtosecond laser-assisted lasik with smile in patients with myopia or myopic astigmatism. J Refract Surg. 2014;30(9):590-596.

15. Hasegawa A, Kojima T, Isogai N, Tamaoki A, Nakamura T, Ichikawa K. Astigmatism correction: laser in situ keratomileusis versus posterior chamber collagen copolymer toric phakic intraocular lens implantation. J Cataract Refract Surg. 2012;38(4):574-581.

16. Reinstein DZ, Gobbe M, Gobbe L, Archer TJ, Carp GI. Optical zone centration accuracy using corneal fixation-based SMILE compared to eye tracker-based femtosecond laser-assisted LASIK for myopia. J Refract Surg. 2015;31(9):586-592.

17. Hashem AN, El Danasoury AM, Anwar HM. Axis alignment and rotational stability after implantation of the toric implantable collamer lens for myopic astigmatism. J Refract Surg. 2009;25(10 Suppl): S939-S943.

18. Mori T, Yokoyama S, Kojima T, et al. Factors affecting rotation of a posterior chamber collagen copolymer toric phakic intraocular lens. J Cataract Refract Surg. 2012;38(4):568-573.
19. Alió JL, Toffaha BT, Peña-Garcia P, Sádaba LM, Barraquer RI. Phakic intraocular lens explantation: causes in 240 cases. J Refract Surg. 2015;31(1):30-35.

20. Pedersen IB, Ivarsen A, Hjortdal J. Three-year results of small incision lenticule extraction for high myopia: refractive outcomes and aberrations. J Refract Surg. 2015;31(11):719-724.

21. Kamiya K, Shimizu K, Saito A, Igarashi A, Kobashi H. Comparison of optical quality and intraocular scattering after posterior chamber phakic intraocular lens with and without a central hole (hole ICL and conventional ICL) implantation using the double-pass instrument. PLoS One. 2013;8(6):e66846.

22. Igarashi A, Kamiya K, Shimizu K, Komatsu M. Visual performance after implantable collamer lens implantation and wavefront-guided laser in situ keratomileusis for high myopia. Am J Ophthalmol. 2009; 148(1):164-170.e1.

23. Perez-Vives C, Dominguez-Vicent A, Ferrer-Blasco T, Pons ÁM, Montés-Micó R. Optical quality of the Visian implantable collamer lens for different refractive powers. Graefes Arch Clin Exp Ophthalmol. 2013;251(5):1423-1429.

24. Miao H, Tian M, Xu Y, Chen Y, Zhou X. Visual outcomes and optical quality after femtosecond laser small incision lenticule extraction: an 18-month prospective study. J Refract Surg. 2015;31(11):726-731.

25. Gyldenkerne A, Ivarsen A, Hjortdal JØ. Comparison of corneal shape changes and aberrations induced By FS-LASIK and SMILE for myopia. J Refract Surg. 2015;31(4):223-229.

26. Lazaridis A, Droutsas K, Sekundo W. Topographic analysis of the centration of the treatment zone after SMILE for myopia and comparison to FS-LASIK: subjective versus objective alignment. J Refract Surg. 2014;30(10):680-686. 


\section{Supplementary material}
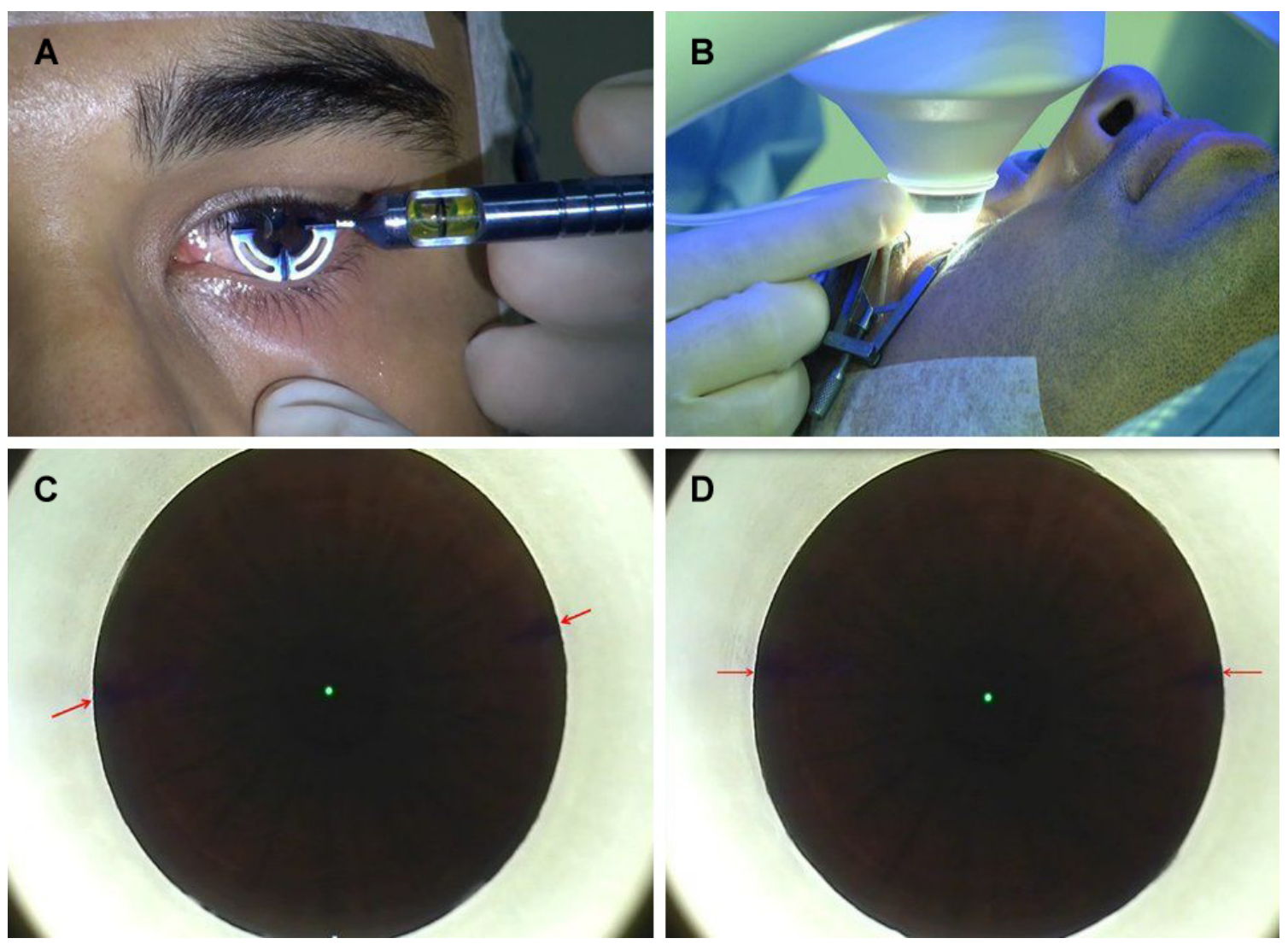

Figure SI (A) Preoperative limbal marking with Ganesh bubble marker under topical anesthesia in upright position. This instrument gives 3 marks on the limbus at $0^{\circ}$, $90^{\circ}$, and $180^{\circ}$, extending $2 \mathrm{~mm}$ toward the center of the cornea which are easy to visualize while the eye is being docked. (B) Method of manual cyclotorsion compensation by a gentle rotation of the cone while holding the same at the attachment of the tube to the cone. (C) Position of the limbal marks (red arrows) under suction "on" condition without cyclotorsion compensation before starting the laser, showing approximately $12^{\circ}$ of cyclotorsion. (D) Final position of the limbal marks after manual compensation of the cyclotorsion error (alignment with the horizontal axis of the eye piece reticule). Delivery of the laser follows this.

\section{Publish your work in this journal}

Clinical Ophthalmology is an international, peer-reviewed journal covering all subspecialties within ophthalmology. Key topics include: Optometry; Visual science; Pharmacology and drug therapy in eye diseases; Basic Sciences; Primary and Secondary eye care; Patient Safety and Quality of Care Improvements. This journal is indexed on

Submit your manuscript here: http://www.dovepress.com/clinical-ophthalmology-journal

\section{Dovepress}

PubMed Central and CAS, and is the official journal of The Society of Clinical Ophthalmology (SCO). The manuscript management system is completely online and includes a very quick and fair peer-review system, which is all easy to use. Visit http://www.dovepress.com/ testimonials.php to read real quotes from published authors. 